\title{
MENINGKATKAN RASA PERSAUDARAAN DAN SOLIDARITAS PERTEMANAN ANTAR SISWA UNTUK MENGHINDARI BULLYING
}

\author{
Asridah Warni Tanjung, Nindie Ellesia, Intan Sari Budiharjo, Umar Hanis \\ Program Studi Manajemen \\ Universitas Pamulang \\ Email: dosen02212@unpam.ac.id
}

\begin{abstract}
The purpose of Community Service Activities is to carry out one of the Higher Education Tri Dharma. In addition, it is expected that through community service, the existence of higher education institutions can make a major contribution to the development and application of knowledge to the community. The method of activity used is that we go to the 26 Bintaro State PKBM school which is located at Jl. Bintaro Permai III / 30B, Ex. Bintaro, Kec. Pesanggrahan, City Administration of South Jakarta and will provide training there on 10-12 October 2019. This training aims to make students and students who attend PKBM 26 Bintaro, especially in the PKBM program, increase fraternity and friendship solidarity between students to avoid bullying in socialize in their environment and the world of work. The results of community service obtained were increased knowledge for Participants (Students) of the 26th State PKBM Bintaro so that they had a good view of the importance of increasing the sense of brotherhood and friendship solidarity among students because of our participation as qualified generations of the nation (HR) for quality entering the world of work and how important it is to improve the quality of themselves to avoid bullying in socializing and the world of work. The knowledge gained at Community Service this time is expected to be able provide new enthusiasm for us in delivering material and motivation and contribute to the younger generation, both within the school, campus and environment family.
\end{abstract}

Keywords: Brotherhood, Solidarity, Bullying

\begin{abstract}
Abstrak
Tujuan dari Kegiatan Pengabdian Kepada Masyarakat adalah untuk melaksanakan salah satu Tri Dharma Perguruan Tinggi. Selain itu diharapkan dengan pengabdian kepada masyarakat tersebut keberadaan perguruan tinggi dapat memberikan kontribusi besar kepada pengembangan dan penerapan keilmuan kepada masyarakat. Metode kegiatan yang digunakan adalah kita mendatangi sekolah PKBM Negeri 26 Bintaro yang
\end{abstract}


beralamt Jl. Bintaro Permai III/30B, Kel. Bintaro, Kec. Pesanggrahan, Kota Administrasi Jakarta Selatan dan akan memberikan pelatihan disana pada tanggal 10-12 Oktober 2019. Pelatihan ini bertujuan agar siswa dan siswi yang bersekolah di PKBM Negeri 26 Bintaro khususnya pada program PKBM dapat meningkatkan rasa persaudaraan dan solidaritas pertemanan antar siswa untuk menghindari bullying dalam bersosialisasi dilingkungan mereka berada dan dunia kerja. Hasil pengabdian masyarakat yang diperoleh adalah bertambahnya keilmuan bagi Para Peserta (Siswa/siswi) PKBM Negeri 26 Bintaro agar mereka memiliki pandangan yang baik tentang pentingnya meningkatkan rasa persaudaraan dan solidaritas pertemanan antar siswa karena peran serta kita sebagai generasi penerus bangsa (SDM) yang berkualitas untuk memasuki dunia kerja dan betapa pentingnya meningkatkan kualitas diri mereka untuk menghindari bullying dalam bersosialisasi dan dunia kerja. Ilmu yang diperoleh pada Pengabdian Masyarakat kali ini diharapkan mampumemberikan semangat baru bagi kita dalam menyampaikan materi dan motivasi serta berkontribusi bagi generasi muda, baik dilingkungan sekolah, kampus dan keluarga.

Kata Kunci: Rasa Persaudaraan, Solidaritas, Bullying

\section{A. PENDAHULUAN}

Pendidikan merupakan salah satu infrastruktur terpenting dalam membangun peradaban dan kemajuan suatu bangsa. Dalam artian, suatu bangsa atau pun Negara dapat dibilang maju atau tidaknya sudah barang tentu sangat bergantung terhadap proses pendidikan yang berjalan didalamnya. Maka, dalam konteks ini perkembangan dan pembangunan dari sektor pendidikan menjadi nilai yang sangat penting, karena pondasi sebuah bangsa terletak pada pendidikannya. Begitupun dengan bangsa Indonesia, meskipun terbilang Negara berkembang Indonesia sangat menomersatukan pendidikan terbukti dari cita-cita bangsa Indonesia yang ingin mencerdaskan kehidupan bangsa, serta telah diatur dalam UU No.20 Tahun 2003 pasal 5 ayat 4, tentang Sistem Pendidikan Nasional bahwa semua warga Negara memiliki potensi serta kecerdasan oleh karenannya mereka berhak mendapatkan pendidikan secara khusus. Sebagaimana dalam bunyi pasal 4 UU No. 23 Tahun 2002 tentang perlindungan anak, menyebutkan bahwa anak mempunyai hak untuk dapat hidup tumbuh, berkembang dan berpartisipasi secara wajar sesuai harkat dan martabat kemanusiaan serta mendapatkan perlindungan dari segala diskriminasi dan segala jenis tindakan kekerasan pada diri anak yang biasa disebut dengan bullying.

Menurut Tumon (2014:2) memberi pandangan bahwa bullying merupakan bentuk tindakan agresif yang permasalahannya sudah mendunia, salah satunya di Indonesia. Kasus tentang bullying di sekolah-sekolah sering kali terjadi disaat ini dan sering terbit di media cetak maupun elektronik. Bullying sendiri menyerang siswa dan siswi dari SD hingga SMA Penyebab dari terjadinya bullying di sekolah sangat beragam, bisa karena siswa dan siswi 
memang sudah terbiasa hidup dalam situasi bullying dan kurangnya pengawasan yang dilakukan oleh guru terhadap segala kegiatan yang dilakukan siswa dan siswi. Sebagai perilaku agresif, bullying tidak bisa didiamkan dan diabaikan begitu saja. Perlu ada upaya dari berbagai pihak untuk mengatasi bullying yang terjadi di sekolah, salah satunya yaitu menjelaskan dan memberi pemahaman kepada siswa dan siswi bagaimana sebuah bullying bisa sangat berdampak besar bagi kehidupan seseorang. Berdasarkan uraian diatas, maka dapat ditarik akar permasalahan dari bullying yang sering terjadi disekolah dasar yaitu disebabkan oleh gagalnya pendidikan karakter. Peristiwa tersebut dapat ditangani dengan melibatkan peran guru, yaitu dengan melakukan pencegahan dan penanaman karakter sedini mungkin serta memberikan pemahaman kepada siswa dan siswi tentang materi Bullying agar mereka paham dan tidak melakukan hal tersebut kepada sesama.

\section{B. METODE PELAKSANAAN KEGIATAN}

Metode kegiatan yang digunakan adalah dengan melakukan kunjungan langsung ke Sekolah PKBM Negeri 26 Bintaro yang beralamt Jl. Bintaro Permai III/30B, Kel. Bintaro, Kec. Pesanggrahan, Kota Administrasi Jakarta Selatan dan akan memberikan pelatihan disana pada tanggal 10-12 Oktober 2019.

Kegiatan pengabdian kepada masyarakat dilakukan dengan metode sebagai berikut:

1. Identifikasi masalah yang dilakukan sebagai langkah awal untuk merumuskan apa saja yang akan dijadikan bahan untuk perancangan sistem dan materi pelatihan dalam kegiatan pengabdian ini.

2. Melakukan survei lapangan ke Sekolah PKBM Negeri 26 Bintaro sebagai tempat dilaksanakannya kegiatan. Kemudian melakukan proses wawancara dan diskusi dengan pihak sekolah untuk identifikasi permasalahan yang ada dalam lingkungan siswa intra sekolah.

Kontribusi pengusul dalam proses pengabdian dengan melakukan penelitian pustaka untuk acuan materi yang digunakan selama kegiatan pengabdian

Pelatihan ini bertujuan agar siswa dan siswi yang bersekolah di PKBM Negeri 26 Bintaro khususnya pada program PKBM dapat meningkatkan rasa persaudaraan dan solidaritas pertemanan antar siswa untuk menghindari bullying dalam bersosialisasi dilingkungan mereka berada dan dunia kerja

\section{HASIL DAN PEMBAHASAN}

Berdasarkan wawancara, tanya jawab dan pengamatan langsung selama kegiatan berlangsung, kegiatan pengabdian pada masyarakat ini memberikan hasil sebagai berikut:

1. Meningkatnya pengetahuan dan pemahaman siswa tentang meningkatkan rasa persaudaraan dan solidaritas pertemanan antar siswa untuk menghindari bullying itu harus diterapkan.

2. Meningkatnya rasa persaudaraan dan solidaritas pertemanan antar siswa untuk menghindari bullying.

Beberapa faktor yang mendukung terlaksananya kegiatan pengabdian pada masyarakat ini adalah besarnya minat dan antusiasme peserta selama kegiatan, sehingga kegiatan 
berlangsung dengan lancar dan efektif. Sedangkan faktor penghambatnya adalah keterbatasan waktu pelatihan dan fasilitas peralatan yang masih minim

\section{KESIMPULAN DAN SARAN}

\section{Kesimpulan}

1. Pengetahuan dan pemahaman siswa dan siswi PKBM Negeri 26 Bintaro tentang meningkatkan rasa persaudaraan dan solidaritas pertemanan antar siswa untuk menghindari bullying menjadi meningkat.

2. Semakin meningkatnya rasa persaudaraan dan solidaritas pertemanan antar siswa untuk menghindari bullying.

\section{Saran}

Mengingat besarnya manfaat kegiatan pengabdian pada masyarakat ini, maka selanjutnya perlu: Mengadakan sosialisasi dan pelatihan serupa pada siswa sekolah lain di Kecamatan yang lain, dengan materi yang serupa. Serta Adanya kesinambungan program pasca kegiatan pengabdian ini sehingga para siswa benar-benar dapat meningkatnya rasa persaudaraan dan solidaritas pertemanan antar siswa untuk menghindari bullying:

\section{DAFTAR PUSTAKA}

Kurniawan. P. (2020), Pengaruh Kecerdasan Intelektual Dan Kecerdasan Emosional Terhadap Kinerja Karyawan Pada PT. Bank Rakyat Indonesia (Persero) Cabang Tangerang Merdeka. Jenius, Vol. 3. No. 3.

Kurniawan, P. (2019), Pengaruh Disiplin Kerja, Motivasi, Dan Komitmen Organisasi Terhadap Kinerja Karyawan Pada PT. Bank Rakyat Indonesia (Persero) Cabang Tangerang Merdeka, Jurnal Ekonomi Efektif, Vol. 1. No. 2.

Sarwono, S. W. (2005). Pesikologi Remaja. Jakarta: PT. Raja

Sejiwa. (2008). Bullying. Jakarta: PT Grasindo.

Sugiyono. (2013). Metode Penelitian Pendidikan. Bandung: Alfabeta. 